\title{
Cranberry intervention in patients with prostate cancer prior to radical prostatectomy. Clinical, pathological and laboratory findings
}

\author{
Vladimir Student ${ }^{a}$, Ales Vidlara , Jan Bouchal ${ }^{b, c}$, Jana Vrbkovac, Zdenek Kolar ${ }^{b, c}$, Milan Kral ${ }^{a}$, Pavel Kosinad ${ }^{d}$, Jitka Vostalova ${ }^{d}$
}

Background and Objectives. Recently, we described an inverse association between cranberry supplementation and serum prostate specific antigen (PSA) in patients with negative biopsy for prostate cancer (PCa) and chronic nonbacterial prostatitis. This double blind placebo controlled study evaluates the effects of cranberry consumption on PSA values and other markers in men with PCa before radical prostatectomy.

Methods. Prior to surgery, 64 patients with prostate cancer were randomized to a cranberry or placebo group. The cranberry group $(n=32)$ received a mean 30 days of 1500 mg cranberry fruit powder. The control group $(n=32)$ took a similar amount of placebo. Selected blood/urine markers as well as free and total phenolics in urine were measured at baseline and on the day of surgery in both groups. Prostate tissue markers were evaluated after surgery.

Results. The serum PSA significantly decreased by $22.5 \%$ in the cranberry arm ( $n=31, P<0.05)$. A trend to down-regulation of urinary beta-microseminoprotein (MSMB) and serum gamma-glutamyltranspeptidase, as well as upregulation of IGF-1 was found after cranberry supplementation. There were no changes in prostate tissue markers or, composition and concentration of phenolics in urine.

Conclusions. Daily consumption of a powdered cranberry fruit lowered serum PSA in patients with prostate cancer. The whole fruit contains constituents that may regulate the expression of androgen-responsive genes.

Key words: Vaccinium macrocarpon, randomized controlled trial, adenocarcinoma, PSA, cancer markers, urinary metabolites.

Received: September 1, 2016; Accepted with revision: November 1, 2016; Available online: November 10, 2016 https://doi.org/10.5507/bp.2016.056

${ }^{a}$ Department of Urology, University Hospital Olomouc, Czech Republic

${ }^{b}$ Department of Clinical and Molecular Pathology, Faculty of Medicine and Dentistry, Palacky University Olomouc, Czech Republic 'Institute of Molecular and Translational Medicine, Faculty of Medicine and Dentistry, Palacky University Olomouc, Czech Republic ${ }^{d}$ Department of Medical Chemistry and Biochemistry, Faculty of Medicine and Dentistry, Palacky University Olomouc, Czech Republic Corresponding authors: Jitka Vostalova, e-mail:j.psotova@email.cz; Ales Vidlar, e-mail:alevi@centrum.cz

\section{INTRODUCTION}

Prostate cancer $(\mathrm{PCa})$ is the second leading cause of cancer death in men in Europe ${ }^{1}$. Advanced age, race, and a family history of $\mathrm{PCa}$ are identifiable risk factors associated with PCa occurrence. Physical activity and diet, modifiable risk factors, have been suggested to play a role in the pathogenesis of $\mathrm{PCa}\left(\mathrm{ref}^{2}{ }^{2}\right)$. Consuming a more plant-based diet for cancer prevention is recommended ${ }^{3}$. Several components derived from edible plants may contribute in reducing the risk of $\mathrm{PCa}\left(\mathrm{ref}^{4}{ }^{4}\right)$. Thus, food components (nutraceuticals) or complex plant extracts act as anti-oxidants, anti-inflammatory remedies, weak $5 \alpha$-reductase inhibitors or target androgen receptor (AR) synthesis and signalling ${ }^{5}$. Molecular mechanisms of the anti-cancer action of natural products were mostly studied on human androgen-dependent and/or independent prostate cell lines. Only a few foods/nutraceuticals have been tested in humans as chemoprotective agents against prostate cancer. Two very recent reviews of intervention clinical trials have been published on: silymarin/silibinin, broccoli sprouts/sulforaphane, pomegranate extract, tomatoes/lycopene, grapes, green tea extract, polyphenols, soybean/genistein, flaxseed/lignans and $\alpha$-linolenic acid, and fish oil/omega-3 fatty acids in men following surgery or radiation for $\mathrm{PCa}\left(\right.$ ref. ${ }^{6,7}$ ).

Cranberry fruit contains several types of components which play a role in its health benefits. These include vitamins $\mathrm{C}, \mathrm{E}, \mathrm{K}$, organic and phenolic acids, saccharides, flavan-3-ols, flavonols, anthocyanins, anthocyanidins, proanthocyanidins and triterpenoids, shown to possess anti-bacterial, anti-viral, anti-oxidant, anti-inflammatory, anti-angiogenic and anti-cancer activities ${ }^{8,9}$. Most of this evidence, with the exception of preventing urinary tract infections, was derived from studies on prostate cancer cell lines ${ }^{10-13}$. Our recent clinical study reported that daily intake of $1500 \mathrm{mg}$ cranberry powder for 6 months significantly reduced total prostate-specific antigen (PSA) elevated from chronic non-bacterial prostatitis, and/or benign prostate hyperplasia ${ }^{14}$. The primary objective of this study was to investigate the effect of the cranberry fruit powder (CFP) supplementation on PSA response in men with PCa. The post-treatment differences between the cranberry and placebo group on basic physiological biomarkers, selected blood inflammatory markers, urine and prostate tissue markers were secondary outcome measures. 


\section{MATERIALS AND METHODS}

\section{Cranberry material}

Cranberry fruit powder (CFP; PACRAN ${ }^{\circledR}$ EUSP_06104, Batch No: A333/132/A12) was supplied by NATUREX-DBS, USA). For structure and content of selected compounds in CFP see Appendix. Capsules of two kinds contained: $500 \mathrm{mg}$ of CFP or $500 \mathrm{mg}$ of placebo of the following composition: low density STAR-DRI ${ }^{\circledR}$ 1015A maltodextrin, canola oil, Red 40 Lake, sodium aluminium silicate and Blue 1 Lake. CFP capsules were indistinguishable in appearance from the placebo capsules. All capsules were provided in plastic boxes with safe seal labelled PACRAN ${ }^{\circledR}$.

\section{Ethics statement, study design, patients, randomization and treatment dose}

The study was conducted at the Department of Urology according to the guidelines laid down in the Declaration of Helsinki (2008 revision). All procedures involving human subjects were approved by the Ethics Committee of the University Hospital and Faculty of Medicine and Dentistry, Palacky University in Olomouc, Czech Republic (reference number 55/12). All participants signed a letter of informed consent.

The study design was a single-center, randomized, placebo-controlled intervention trial consisting of two parallel treatment arms. The enrollment began in May 2012 with follow-up complete in May 2013. To be eligible, the patient had to have a pathological diagnosis of adenocarcinoma of the prostate from prostate biopsy. Other inclusion criteria were $\mathrm{BMI}<37$, normal liver function test, normal range of blood pressure and heart rate. The exclusion criteria were current antibiotic use (antibiotics reduce the intestinal microflora) or history of hormonal and radiation therapies or chemotherapy. Before study entry, patients medical history was taken and a physical examination, complete blood count and clinical chemistry profile.

The subjects ( $n=64)$ were randomly assigned to either cranberry group, a daily dose $1500 \mathrm{mg}$ dry cranberry fruit powder $(n=32)$ or placebo group $(n=32)$ at least 21 days before surgery. The randomization plan for treatment assignment to patients was generated using on line software QuickCales (GraphPad Software Inc., USA). Suggested clinical dosing of cranberry fruit powder was based on our study in men at risk of prostate disease ${ }^{14}$. Patients were instructed not to consume food rich in color pigment (anthocyanin-containing fruit) or soy products or to make other dietary or lifestyle changes during the study. Compliance was assessed by performing a remaining capsule counts at the end of the intervention when the patients were admitted to the hospital for surgery.

Blood and urine samples for clinical chemistry, hematology and urine analysis were collected on the first day at registration and after intervention immediately before surgery. The prostatectomy specimens were embedded in paraffin, step-sectioned, and microscopically examined.

\section{Clinical chemistry and hematology}

Basic biochemical and hematological parameters were determined. Total cholesterol, low density lipoprotein (LDL), high density lipoprotein (HDL), triacylglycerols (TAG), C-reactive protein (CRP), alanine aminotransferase (ALT), gamma-glutamyltranspeptidase (GGT), glycaemia, creatinine, blood urea nitrogen (BUN) and interleukin-6 (IL-6) were quantified in serum using a Cobas (Hitachi, Japan). Testosterone (TST) and prostate specific antigen (PSA) in serum was determined using an Architect i2000SR (Abbott, USA). Insuline-like growth factor-1 (IGF-1), insulin-like growth factor binding protein (IGFP) and free testosterone (fTST) were quantified in serum using a RIA kits by Cobra 5005 analyzer (Packard BioInstruments, USA).

Selected hematological parameters were measured.

Selected parameters for evaluation of oxidative stress total sulphydryl groups (TSHG), lipid peroxidation products such as malondialdehyde in plasma (PMDA) and erythrocytes (MDA), glutathione (GSH), glutathione peroxidase (GSHPer), glutathione reductase (GSHRed), superoxide dismutase (SOD) and catalase in erythrocytes were carried out as described by Vidlar et al. ${ }^{14}$. Paraoxonase 1 (PON1) activity was measured according to Sumegova et al. ${ }^{15}$. Plasma 8-hydroxydeoxyguanosine (8-OHdG) was measured by OxiSelect ${ }^{\mathrm{TM}}$ Oxidative DNA Damage ELISA, 8-OHdG Quantification kit. Plasma selenium and zinc were determined by inductively coupled plasma mass spectrometry (Agilent 7700x, Agilent Japan) using octapole reaction cell in He mode to eliminate spectral interference. The determination was performed by external calibration. Calibration solutions were prepared by diluting certified reference materials - water calibration solutions of Se and $\mathrm{Zn}$ with concentration 1.000 +/- 0.002 $\mathrm{mg} / \mathrm{L}$ (Analytika Ltd, Czech Republic). Prior to ICP-MS determination blood plasma samples were digested in microwave mineralizator (Meg $1200 \mathrm{mls}$, Milestone, Italy) with mixture of $\mathrm{HNO}_{3}$ (Analpure, Analytika Ltd, Czech Republic) and $\mathrm{H}_{2} \mathrm{O}_{2}$ (analytical grade, Analytika Ltd., Czech Republic).

\section{RNA urine markers}

Urine samples were collected and analyzed as described previously ${ }^{16}$. Briefly, a portion of the first voided urine after an "attentive" prostate massage was used. Total RNA was isolated, quantified and reverse transcribed. The quantitative real-time PCR (qPCR) reactions were performed with specific primers and probes for AMACR, PCA3, EZH2, MSMB, PSA and TRPM8 on LightCycler ${ }^{\circledR}$ 480 , Roche. After relative quantification $\left(\Delta \mathrm{C}_{\mathrm{t}}=\mathrm{C}_{\mathrm{t} \text { target }}\right.$ $\left.-\mathrm{C}_{\mathrm{tPSA}}\right)$ inverse values of $\Delta \mathrm{C}_{\mathrm{t}}\left(-\Delta \mathrm{C}_{\mathrm{t}}\right)$ were used for subsequent statistical analysis and visualization ${ }^{17}$. As the first step, we evaluated the urine samples after treatment with placebo or cranberry. With respect to mild changes between placebo and cranberry arms, we also analyzed the first urine samples (before treatment) for 39 patients [other patient samples were not included for the following reasons: urine samples were not collected $(n=3)$, urine RNA had low concentration $(n=3)$ or results of qRT-PCR 


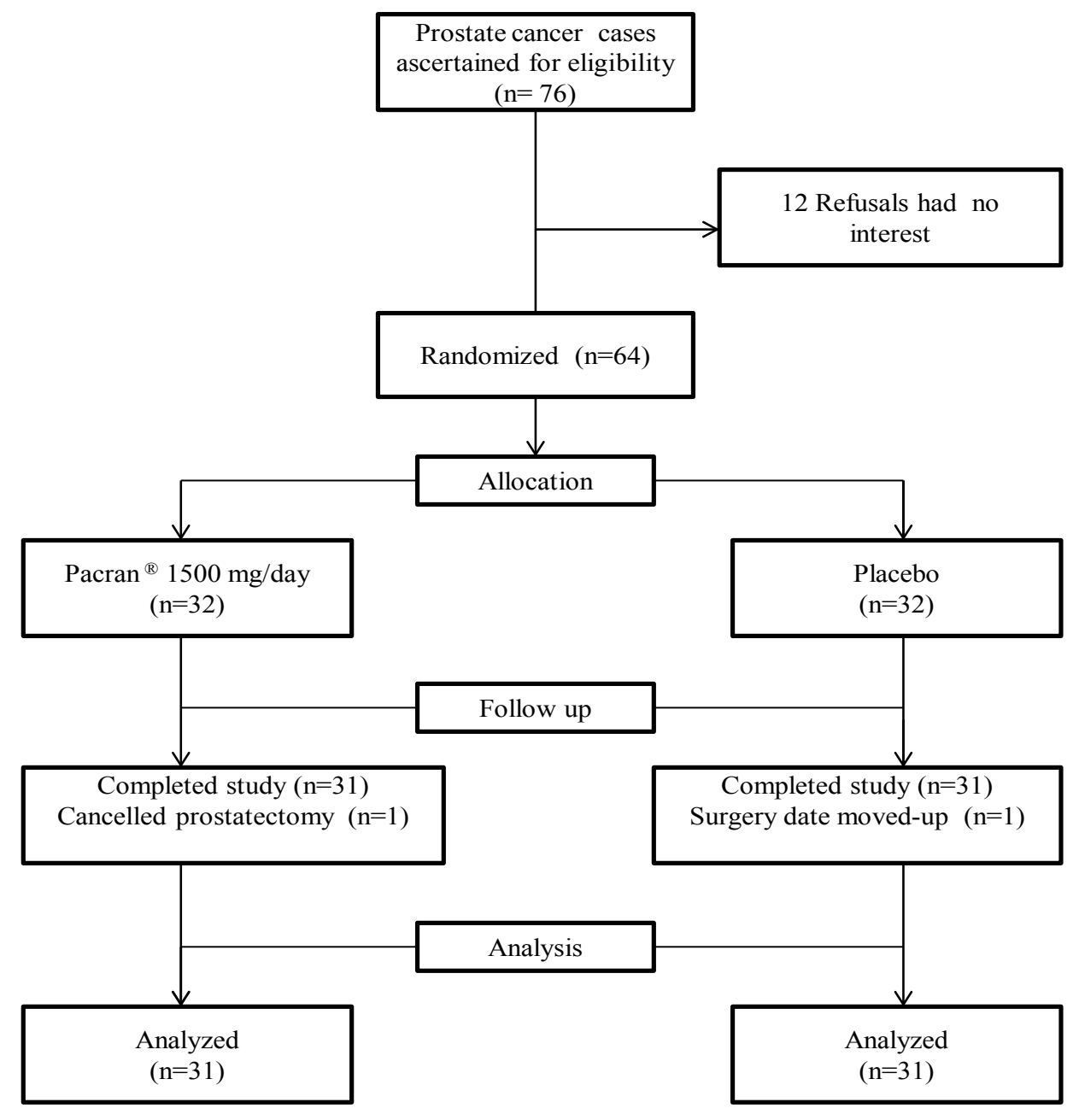

Fig. 1. CONSORT trial flow diagram.

after treatment were non-evaluable because of negative or low expression of PSA mRNA $(n=17)$.

\section{Specimen collection and immunohistochemistry}

The prostatectomy specimens were formalin-fixed, paraffin-embedded, and sectioned for routine examination by indirect immunohistochemistry. Five-micron thick sections with representative tumor and surrounding areas were stained with the following antibodies and dilutions: Ki-67 at 1:200 (clone MIB-1, Dako); Chromogranin A at 1:100 (clone 5H7, Novocastra); PSMA at 1:100 (clone YPSMA, Abcam); AR at 1:100 (clone AR441, Dako); NF-kB p65 at 1:400 (clone F-6, Santa Cruz) and COX2 at 1:50 (clone M-19, Santa Cruz). Visualization was performed by the DakoREAL ${ }^{\mathrm{TM}}$ EnVision $^{\mathrm{TM}_{+}}$Dual Link System-HRP and Dako Liquid DAB plus Substrate Chromogen System.

\section{Statistical methods}

Data were analyzed with statistical software R (http:// www.r-project.org/). Instead of absolute values, the differences in time were used for computations with continuous parameters. Student's two-sample t-test (between groups comparison of differences in time) and Student's one-sample t-test (tests of location - zero differences in time) were used for normally distributed data (tested with the Shapiro-Wilk normality test), otherwise nonparametric Wilcoxon two-sample or one-sample tests were used. Categorical data were analyzed with Fisher's exact rank tests. Graphs of empirical cumulative distribution functions were used as a graphical data representation.

\section{RESULTS}

Patient recruitment is depicted in Fig. 1. We invited 76 patients aged 45 to 75 years who were scheduled to undergo radical prostatectomy as their primary treatment and at least 21 days before surgery. Twelve patients had no interest to take part in a trial. There were no significant differences between the cranberry and placebo groups with regard to age, body mass index (BMI), plasma concentrations of zinc and selenium (Table 1). Median range of Gleason score was 7 (6.7) for cranberry and 7 (7.7) for placebo group. With regard to other factors, patients in the cranberry group had a statistically significant higher initial PSA values than those of the placebo group. Table 2 shows preoperative (clinical) and postoperative (pathological) $\mathrm{T}$ stage for patients in both groups. There is no significant difference between cranberry and placebo can- 
Table 1. Patient baseline demographics and clinical characteristics.

\begin{tabular}{llcc}
\hline Parameter & Unit & Cranberry group $(\mathrm{n}=31)$ & Placebo group $(\mathrm{n}=31)$ \\
\hline Age & Years & $62.5 / 66.0 / 68.0$ & $61.0 / 64.0 / 68.5$ \\
BMI & $\mathrm{kg} / \mathrm{m}^{2}$ & $24.8 / 27.8 / 28.7$ & $25.8 / 26.9 / 29.1$ \\
Initial PSA & $\mathrm{ng} / \mathrm{mL}$ & $6.2 / 8.8 / 13.6$ & $3.7 / 5.4 / 9.3^{\#}$ \\
Zinc & $\mathrm{mg} / \mathrm{L}$ & $0.981 / 1.174 / 1.438$ & $1.034 / 1.225 / 1.577$ \\
Selenium & $\mathrm{ng} / \mathrm{mL}$ & $97.1 / 120.1 / 131.0$ & $102.7 / 120.1 / 142.7$ \\
Prostate volume & $\mathrm{mL}$ & $49.3 / 57.5 / 65.0$ & $40.5 / 49.0 / 61.0$ \\
Gleason score & & $\mathrm{n}(\%)$ & $\mathrm{n}(\%)$ \\
5 & & $2(6.45)$ & $2(6.45)$ \\
6 & & $7(22.58)$ & $4(12.90)$ \\
7 & & $19(61.29)$ & $25(80.65)$ \\
8 & & $1(3.23)$ & 0 \\
9 & & $2(6.45)$ & 0 \\
\hline
\end{tabular}

The values are expressed as first quartile, median and third quartile.

${ }^{\text {\#} S i g n i f i c a n t ~ d i f f e r e n c e ~ b e t w e e n ~ C r a n b e r r y ~ a n d ~ P l a c e b o ~ g r o u p s ~ b y ~ t w o-s a m p l e ~ W i l c o x o n ~ t e s t ~} P<0.1$

Table 2. Histopathological preoperative and postoperative $\mathrm{T}$ stage.

\begin{tabular}{cccclcrr}
\hline & \multicolumn{3}{c}{ Preoperative T stage, $\mathrm{n}$} & \multicolumn{3}{c}{ Postoperative T stage, $\mathrm{n}$} \\
\multicolumn{2}{c}{ Cranberry group } & \multicolumn{2}{c}{ Placebo group } & \multicolumn{2}{l}{ Cranberry group } & Placebo group \\
\hline T1a-T1c & 21 & T1a-T1c & 22 & pT2a & 3 & pT2a & 2 \\
T2a & 2 & T2a & 4 & pT2b & 3 & pT2b & 2 \\
T2b & 5 & T2b & 2 & pT2c & 17 & pT2c & 20 \\
T2c & 3 & T2c & 3 & pT3a & 5 & pT3a & 4 \\
& & & & pT3b & 3 & pT3b & 3 \\
\hline
\end{tabular}

Table 3. Markers of hematology.

\begin{tabular}{lccccc}
\hline & & \multicolumn{2}{c}{ Cranberry group } & \multicolumn{2}{c}{ Placebo group } \\
Parameter & Unit & Start Day & End Day & Start Day & End Day \\
\hline $\mathrm{Htc}$ & & $0.43 / 0.44 / 0.46$ & $0.42 / 0.44 / 0.46^{* * ; \# \#}$ & $0.43 / 0.44 / 0.46$ & $0.43 / 0.45 / 0.46^{\# \#}$ \\
$\mathrm{Hb}$ & $\mathrm{g} / \mathrm{L}$ & $145.5 / 151.0 / 155.0$ & $142.5 / 149.0 / 156.0$ & $143.0 / 150.0 / 156.0$ & $145.0 / 149.0 / 157.5$ \\
$\mathrm{PLT}$ & $\mathrm{x} 10(9) / \mathrm{L}$ & $187.5 / 232.0 / 257.0$ & $184.0 / 207.0 / 249.0$ & $189.5 / 223.0 / 266.5$ & $190.0 / 233.0 / 258.5$ \\
$\mathrm{RBC}$ & $\mathrm{x} 10(12) / \mathrm{L}$ & $4.71 / 4.91 / 5.20$ & $4.64 / 4.88 / 5.17$ & $4.74 / 4.92 / 5.11$ & $4.70 / 4.91 / 5.21$ \\
$\mathrm{WBC}$ & $\mathrm{x} 10(9) / \mathrm{L}$ & $5.54 / 6.40 / 7.25$ & $5.32 / 6.20 / 7.03$ & $5.90 / 6.49 / 7.62$ & $5.80 / 7.42 / 7.85$ \\
\hline
\end{tabular}

The values are expressed as first quartile, median and third quartile.

${ }^{* *}$ Significant difference between value of Start day by one-sample Wilcoxon test $P<0.05$

\# Significant difference between value of Cranberry and Placebo group by two-sample Wilcoxon test $P<0.05$

** One-sample Wilcoxon test, $P<0.05$; \#\#To-sample Wilcoxon test, $P<0.05$

Abbreviations used: Hct (hematocrit), Hb (hemoglobin), PLT (platelets), RBC (red blood cells), WBC (white blood cells).

cer staging scores before $(P=0.617)$ or after prostatectomy $(P=0.943)$.

Hematology values were unchanged with the exception of hematocrit value but the fluctuations were within normal physiological limits (Table 3 ).

Serum PSA concentration decreased by $22.5 \%$ in the cranberry group, whereas the concentration increased by $0.9 \%$ in the placebo group over the study period (Table 4). There was also a trend towards increased IGF-1 and decreased GGT in the cranberry group. There were no significant differences in other clinical chemistry parameters.

The oxidative stress markers are shown in Table 5. Highly statistically significant differences for the cranberry group were found for erythrocyte malondialdehyde (MDA), plasma malondialdehyde (PMDA), total thiol groups (TSHG), catalase and for placebo group in MDA, PMDA, paraoxonase 1 (PON1) and glutathione peroxidase (GSHPer).

Table 6 shows selected markers for detection of prostate cancer in urine. A trend to down-regulation of beta-microseminoprotein (MSMB) after cranberry supplementation was observed along with up-regulation of PCA3.

The results of immunohistochemical evaluation are shown in Table 7. There were no significant differences between cranberry and placebo groups.

Phenolics in the urine were analysed directly without enzymatic cleavage and then after further incubation with a mixture of deconjugation enzymes, $\beta$-glucuronidase and sulfatase (for details see Appendix, Table II and III). There was no significant difference in free or total pheno- 
Table 4. Markers of clinical chemistry.

\begin{tabular}{llcccc}
\hline & & \multicolumn{2}{c}{ Cranberry group } & \multicolumn{2}{c}{ Placebo group } \\
Parameter & Unit & Start Day & End Day & Start Day & End Day \\
\hline ALT & $\mu \mathrm{kat} / \mathrm{L}$ & $0.37 / 0.43 / 0.49$ & $0.39 / 0.44 / 0.55$ & $0.35 / 0.45 / 0.49$ & $0.37 / 0.45 / 0.53$ \\
GGT & $\mu \mathrm{kat} / \mathrm{L}$ & $0.41 / 0.47 / 0.77$ & $0.37 / 0.45 / 0.76^{*}$ & $0.37 / 0.58 / 0.72$ & $0.39 / 0.49 / 0.84$ \\
Creatinine & $\mu \mathrm{mol} / \mathrm{L}$ & $78.5 / 83.0 / 89.5$ & $76.5 / 86.0 / 90.0$ & $74.5 / 81.0 / 87.0$ & $77.5 / 82.0 / 88.0$ \\
BUN & $\mathrm{mmol} / \mathrm{L}$ & $4.8 / 5.1 / 5.8$ & $4.8 / 5.4 / 5.8$ & $4.6 / 5.2 / 5.7$ & $4 / 4.9 / 5.6$ \\
Glucose & $\mathrm{mmol} / \mathrm{L}$ & $5.2 / 5.7 / 6.4$ & $5.1 / 5.5 / 6.2$ & $5.1 / 5.6 / 6.4$ & $5.3 / 5.7 / 6.7$ \\
TAG & $\mathrm{mmol} / \mathrm{L}$ & $1.05 / 1.38 / 1.66$ & $1.028 / 1.29 / 1.69$ & $1.315 / 1.67 / 2.51$ & $1.235 / 1.65 / 2.19$ \\
Cholesterol & $\mathrm{mmol} / \mathrm{L}$ & $4.32 / 4.95 / 5.90$ & $4.23 / 4.92 / 5.94$ & $4.67 / 5.22 / 6.01$ & $4.64 / 5.26 / 6.29$ \\
LDL & $\mathrm{mmol} / \mathrm{L}$ & $2.25 / 2.69 / 3.82$ & $2.24 / 2.84 / 3.78$ & $2.55 / 3.01 / 3.66$ & $2.46 / 3.07 / 3.81$ \\
HDL & $\mathrm{mmol} / \mathrm{L}$ & $1.21 / 1.39 / 1.79$ & $1.26 / 1.41 / 1.63$ & $1.08 / 1.28 / 1.34$ & $1.17 / 1.23 / 1.47$ \\
CRP & $\mathrm{mg} / \mathrm{L}$ & $0.75 / 1.20 / 2.20$ & $0.70 / 1.00 / 1.60$ & $0.60 / 1.10 / 2.75$ & $0.38 / 1.05 / 2.55$ \\
Il-6 & $\mathrm{ng} / \mathrm{L}$ & $1.5 / 2.9 / 3.95$ & $2 / 2.9 / 3.75$ & $1.525 / 2.6 / 3.8$ & $1.5 / 2.7 / 3.65$ \\
IGF-1 & $\mu \mathrm{g} / \mathrm{L}$ & $105 / 137 / 161$ & $113 / 149 / 174 *$ & $113 / 138 / 170$ & $121 / 142 / 164$ \\
IGFP & $\mu \mathrm{g} / \mathrm{L}$ & $2089 / 2590 / 2855$ & $2148 / 2568 / 2853$ & $2342 / 2581 / 2879$ & $2337 / 2541 / 3090$ \\
TST & $\mathrm{nmol} / \mathrm{L}$ & $11.92 / 15.39 / 21.57$ & $11.26 / 15.17 / 17.68$ & $11.34 / 14.58 / 18.79$ & $11.86 / 14.81 / 17.03$ \\
fTST & $\mathrm{nmol} / \mathrm{L}$ & $24.63 / 30.55 / 39.75$ & $19.75 / 27.75 / 36.10$ & $25.00 / 31.30 / 35.70$ & $24.25 / 28.50 / 36.20^{*}$ \\
PSA & $\mathrm{ng} / \mathrm{mL}$ & $6.23 / 8.83 / 13.59$ & $4.54 / 6.84 / 13.03^{* *}$ & $3.68 / 5.38 / 9.33$ & $3.62 / 5.43 / 9.05^{* *}$ \\
\hline
\end{tabular}

The values are expressed as first quartile, median and third quartile.

"Significant difference between value of Start day by one-sample Wilcoxon test $P<0.1$

${ }^{* *}$ Significant difference between value of Start day by one-sample Wilcoxon test $P<0.05$

*One-sample Wilcoxon test, $P<0.1$; ${ }^{* *}$ One-sample Wilcoxon test, $P<0.05$

Table 5. Markers of oxidative stress in blood.

\begin{tabular}{llcccc}
\hline & & \multicolumn{2}{c}{ Cranberry group } & \multicolumn{2}{c}{ Placebo group } \\
Parameter & Unit & Start Day & End Day & Start Day & End Day \\
\hline MDA & $\mathrm{nmol} / \mathrm{g}^{\mathrm{a}}$ & $18.51 / 20.67 / 23.62$ & $23.66 / 26.72 / 29.71^{* *}$ & $18.65 / 20.98 / 25.28$ & $23.18 / 27.41 / 32.45^{* *}$ \\
GSH & $\mu \mathrm{mol} / \mathrm{g}^{\mathrm{a}}$ & $6.97 / 7.85 / 8.92$ & $6.93 / 8.01 / 9.03$ & $6.97 / 8.04 / 8.58$ & $7.01 / 7.84 / 9.07$ \\
PMDA & $\mathrm{nmol} / \mathrm{g}^{\mathrm{b}}$ & $82.8 / 103.5 / 119.8$ & $81.2 / 115.1 / 151.8^{* *}$ & $70.9 / 105.0 / 132.7$ & $84.3 / 113.6 / 135.9^{* *}$ \\
TSHG & $\mu \mathrm{mol} / \mathrm{g}^{\mathrm{b}}$ & $6.50 / 7.24 / 8.12$ & $6.99 / 7.69 / 8.56^{* *}$ & $6.47 / 6.79 / 8.49$ & $6.88 / 7.48 / 8.42^{*}$ \\
PON1 & $\mu \mathrm{kat} / \mathrm{L}$ & $0.83 / 1.50 / 2.00$ & $0.79 / 1.31 / 2.14$ & $0.75 / 1.23 / 2.29$ & $0.70 / 1.43 / 2.43^{*}$ \\
$8-\mathrm{OHdG}$ & $\mu \mathrm{g} / \mathrm{L}$ & $7.57 / 9.03 / 11.20$ & $8.55 / 9.87 / 11.95$ & $6.90 / 8.74 / 11.02$ & $6.66 / 9.19 / 11.18$ \\
Catalase & $\mu \mathrm{kat} / \mathrm{g}^{\mathrm{a}}$ & $1.12 / 1.19 / 1.43$ & $1.17 / 1.30 / 1.46^{* *}$ & $1.07 / 1.32 / 1.49$ & $1.11 / 1.39 / 1.47$ \\
GSX & $\mu \mathrm{kat} / \mathrm{g}^{\mathrm{a}}$ & $1.54 / 2.17 / 2.92$ & $1.40 / 1.87 / 2.37^{*}$ & $1.86 / 2.25 / 2.84$ & $1.18 / 1.69 / 2.19^{* *}$ \\
GSR & $\mu \mathrm{kat} / \mathrm{g}^{\mathrm{a}}$ & $0.21 / 0.25 / 0.29$ & $0.22 / 0.25 / 0.28$ & $0.20 / 0.23 / 0.28$ & $0.21 / 0.24 / 0.31^{*}$ \\
SOD & $\mathrm{U} / \mathrm{g}^{\mathrm{a}}$ & $3.09 / 3.28 / 3.51$ & $3.00 / 3.41 / 3.65$ & $3.10 / 3.34 / 3.62$ & $3.17 / 3.39 / 3.83$ \\
\hline
\end{tabular}

The values are expressed as first quartile, median and third quartile.

${ }^{\mathrm{a}} \mathrm{g}$ of hemoglobin; ${ }^{\mathrm{b}} \mathrm{g}$ of protein

"Significant difference between value of Start day by one-sample Wilcoxon test $P<0.1$

${ }^{* *}$ Significant difference between value of Start day by one-sample Wilcoxon test $P<0.05$

"One-sample Wilcoxon test, $P<0.1$; ${ }^{* *}$ One-sample Wilcoxon test, $P<0.05$

lics between the groups. No anthocyanins or proanthocyanidins were detected in urine.

\section{DISCUSSION}

Cranberry products, fresh or dry fruit, juice, dietary supplements containing juice powder or powdered fruit, are used mainly in protection against recurrent urinary tract infection in women ${ }^{21}$ and improvement of lower urinary parameters in men with moderate to severe LUTS $\left(\right.$ ref. $\left.^{22}\right)$. Studies on the possible effects of cranberry and its components on prostate cancer were realized only in DU 145 human prostate cancer cells which are androgen independent. Treatment of cranberry proanthocyanidin- enriched fraction inhibited matrix metalloproteinase-2 and -9 (MMP) activity through the induction and/or inhibition of specific temporal MMP regulators ${ }^{10}$. MMP activity is associated with tumor cell invasion and metastasis. Cranberry fruit contains a high amount of ursolic acid and its esters. The ability of these components to inhibit MMP-2 and MMP-9 was determined in DU 145 cells ${ }^{11}$. Treatment of DU145 cells with the whole cranberry extract, flavonol-enriched or proanthocyanidinenriched fractions induced apoptosis in cells through caspase- 8 activation ${ }^{12}$.Treatment of whole cranberry extract significantly decreased the cellular viability of DU145 cells. It also decreased the proportion of cells in the G2-M phase and increased the proportion in the G1 phase of the cell cycle. These alterations in cell cycle 
Table 6. RNA urine markers.

\begin{tabular}{lccccc}
\hline & & \multicolumn{2}{c}{ Cranberry group } & \multicolumn{2}{c}{ Placebo group } \\
Parameter & Units & Start Day & End Day & Start Day & End Day \\
\hline RNA & $\mathrm{ng} / \mathrm{mL}$ & $8.23 / 17.46 / 37.23$ & $5.16 / 10.55 / 15.22^{*}$ & $7.37 / 17.19 / 42.52$ & $7.48 / 13.70 / 33.25$ \\
Ct PSA & $\mathrm{dCt}$ & $32.30 / 34.21 / 35.61$ & $30.79 / 34.17 / 35.85$ & $31.41 / 34.02 / 35.83$ & $32.70 / 34.66 / 36.97$ \\
AMACR & $-\mathrm{dCt}$ & $-4.21 /-1.90 /-0.79$ & $-4.25 /-2.61 /-0.87$ & $-3.47 /-2.19 /-0.60$ & $-3.45 /-2.35 /-1.12$ \\
PCA3 & $-\mathrm{dCt}$ & $-5.41 /-4.44 /-3.34$ & $-4.26 /-3.30 /-2.71^{* *}$ & $-5.27 /-3.08 /-2.68$ & $-3.87 /-3.26 /-2.58$ \\
TRPM8 & $-\mathrm{dCt}$ & $-4.58 /-3.98 /-3.59$ & $-4.31 /-4.03 /-3.03$ & $-4.92 /-4.41 /-3.69$ & $-5.09 /-4.56 /-4.33$ \\
MSMB & $-\mathrm{dCt}$ & $-0.55 / 0.29 / 0.70$ & $-0.72 /-0.18 / 0.76^{*} ;$ & $-0.56 /-0.27 / 0.51$ & $-0.74 /-0.13 / 0.53^{\#}$ \\
EZH2 & $-\mathrm{dCt}$ & $-2.16 / 0.81 / 1.93$ & $-1.73 /-0.20 / 1.13$ & $-1.40 / 0.04 / 2.19$ & $-2.52 / 0.46 / 1.92$ \\
\hline
\end{tabular}

The values are expressed as first quartile, median and third quartile.

*Significant difference value of Start day by one-sample Wilcoxon test $P<0.1$; **Significant different value of Start day by one-sample Wilcoxon test $P<0.05$

\#Significant difference value of Cranberry and Placebo group by two-sample Wilcoxon test $P<0.1$

*One-sample Wilcoxon test, $P<0.1$

**One-sample Wilcoxon test, $P<0.05$

"Two-sample Wilcoxon test, $P<0.1$

Table 7. Specific markers in ex vivo prostate tissue.

\begin{tabular}{llcc}
\hline Parameter & Unit & Cranberry group & Placebo group \\
\hline Ki67 & \% of positivity & $3.0 / 5.0 / 10.0$ & $3.0 / 7.5 / 10.0$ \\
Chromogranin A & \% & $0.0 / 0.0 / 0.5$ & $0.0 / 0.0 / 0.0$ \\
PSMA $^{\mathrm{b}}$ & See legendivity & $1.00 / 2.00 / 3.00$ & $1.00 / 2.00 / 2.75$ \\
AR $^{\mathrm{c}}$ & Histoscore & $90 / 150 / 150$ & $90 / 100 / 150$ \\
p65 NF-kB $^{\mathrm{c}}$ & Histoscore & $100 / 150 / 200$ & $150 / 175 / 200$ \\
COX-2 $^{\mathrm{c}}$ & Histoscore & $150 / 200 / 200$ & $150 / 200 / 200$ \\
\hline
\end{tabular}

The values are expressed as first quartiles, median and third quartiles.

apercentage of positivity above $5 \%$ was present only in two patients from Cranberry group.

'PSMA was evaluated as follows: 0 , absent; 1 , weak positivity in some glands; 2 , medium positivity in less than half of glands; 3 , strong positivity in more than half of glands or medium positivity in majority of glands. ${ }^{\mathrm{c}}$ Histoscore; \% of positivity multiplied by staining intensity ( 0 , absent; 1 , weak; 2 , moderate; and 3 , strong), resulting in histoscore from 0 to 300 .

were associated with changes in cell cycle regulatory proteins ${ }^{13}$.

Findings from the above in vitro studies suggest that whole cranberry extract or at least 3 key types/categories of components, flavonols, proanthocyanidins or triterpenoids, are associated with biological alteration of cell targets and may be protective for PCa. The effects of cranberry on PCa in humans, to the best our knowledge, have not yet been reported. In this study, we evaluated, in a randomized, double-blind, placebo control trial (RCT) the effects of CFP on blood, urine and prostate tissue markers in PCa patients. The daily dose $1500 \mathrm{mg}$ CFP was given to men with $\mathrm{PCa}$ for at least 21 days (mean, SD were $31 \pm 9$ days in the cranberry group and $35 \pm 8$ days in placebo group) before radical prostatectomy. The intervention was well-tolerated. On the day of surgery, there was a marked decrease of $22.5 \%$ in PSA level in the cranberry arm and a small increase of $0.9 \%$ in the placebo arm. This is in good concordance with our previous study on cranberry effects in men with non-bacterial prostatitis $^{14}$. The down-regulation of serum PSA may be related a trend to down-regulation of beta-microseminoprotein (MSMB) which has been reported to be androgen regulated ${ }^{18-20}$. Unexpectedly, there was enhanced expression of PCA3 in the cranberry arm. The trend to downregulation of MSMB after cranberry supplementation is more reliable than upregulation of PCA3 due to larger number of successful test results for both time points ( 19 for MSMB and only 8 PCA 3 in the cranberry arm). Interestingly, 6/9 patients with downregulation of MSMB had also downregulation of serum PSA. Furthermore, Martinez-Pinero et al. showed that urinary PCA3 is not a reliable marker of cancer stage or response to androgen-deprivation therapy in advanced prostate cancer ${ }^{23}$. The significant increase of malondialdehyde levels in plasma and erythrocytes between start and end day in both groups may be evidence that cranberry consumption was not effective in inhibiting oxidative stress in PCa patients.

\section{CONCLUSION}

These data suggest that further studies to evaluate cranberry consumption as a prophylactic against the biochemical recurrence of prostate cancer in patients after surgery is warranted.

Acknowledgments: Financial support from the Institutional Support of Palacky University in Olomouc, grants NV15-28628A, RVO: FNOL00098892 from the 
Czech Ministry of Health and NPS I LO1304, RVO: 61989592 from the Czech Ministry of Education are gratefully acknowledged. The authors thank Walmark, a.s. providing the cranberry/placebo capsules, the patients for participating in the study and the following individuals who helped to facilitate this trial: Natasa Sochorova, Jana Knillova, Jana Holinkova, Jitka Stastna and Eva Leparova, as well as David Milde, Ph.D. for determination of zinc and selenium and Prof Jitka Ulrichova for helpful discussion on the manuscript.

Author contributions: VS: manuscript preparation; AV: management of clinical trial; JB: prostate cancer markers; ZK: morphological examinations; JVr: statistical evaluation; MK: patient recruitment and data collection; PK: analytical methods; JVo: laboratory assays.

Conflict of interest statement: The authors state that there are no conflicts of interest regarding the publication of this article.

\section{REFERENCES}

1. Ferlay J, Steliarova-Foucher E, Lortet-Tieulent J, Rosso S, Coebergh JWW, Comber H, Forman D, Bray F. Cancer incidence and mortality patterns in Europe: estimates for 40 countries in 2012. Eur J Cancer 2013;49(6):1374-403. doi: 10.1016/j.ejca.2012.12.027

2. Hackshaw-McGeagh LE, Perry RE, Leach VA, Qandil S, Jeffreys M, Martin RM, Lane JA. A systematic review of dietary, nutritional, and physical activity interventions for the prevention of prostate cancer progression and mortality. Cancer Causes Control 2015;26(11):152150.

3. Mayne ST, Playdon MC, Rock CL. Diet, nutrition, and cancer: past, present and future. Natur Rev Clinical Oncol 2016; doi: 10.1038/ nrcliorc2016.24

4. Willis MS, Wians Jr. FH. The role of nutrition in preventing prostate cancer: a review of the proposed mechanism of action of various dietary substances. Clin Chim Acta 2003;330:57-83.

5. Kallifatidis G, Hoy J, Lokeshwar BL. Bioactive products for chemoprevention and treatment of castration-resistant prostate cancer. Semin Cancer Biol 2016, http//dx.doi.org/10.1016/j.semcancer.201606003.

6. Hussain SS, Kumar AP, Ghosh R. Food-based natural products for cancer management: Is the whole greater than the sum of the parts? Semin Cancer Biol 2016 Jul 7. pii: S1044-579X(16)30022-0. doi: 10.1016/j.semcancer.2016.06.002

7. Aucoin M, Cooley ND, Knee C, Fritz H, Balneaves LG, Breau R, Fergusson D, Skidmore B, Wong R, Seely D. Fish-Derived Omega-3 Fatty Acids and Prostate Cancer: A Systematic Review. Integr Cancer Ther 2016 Jun 29. pii: 1534735416656052.

8. Blumberg JB, Camesano TA, Cassidy A, Kris-Etherton P, Howell A Manach C, Ostertag LM, Sies H, Skulas-Ray A, Vita JA.Cranberries and their bioactive constituents in human health. Adv Nutr 2013;4:618-32.

9. Katsargyris A, Tampaki EC, Giaginis C, Theocharis S. Cranberry as promising natural source of potentional anticancer agents: current evidence and future perspectives. Anticancer Agents Med Chem 2012;12(6):619-30.

10. Déziel BA, Patel K, Neto CC, Gottschall-Pass K, Hurta RA. Proanthocyanidins from the American Cranberry (Vaccinium macrocarpon) inhibit matrix metalloproteinase-2 and matrix me- talloproteinase-9 activity in human prostate cancer cells via alterations in multiple cellular signalling pathways. J Cell Biochem 2010;111(3):742-54.

11. Kondo M, MacKinnon SL, Craft CC, Matchett MD, Hurta RA, Neto CC. Ursolic acid and its esters: occurrence in cranberries and other Vaccinium fruit and effects on matrix metalloproteinase activity in DU145 prostate tumor cells. J Sci Food Agric 2011;91(5):789-96.

12. MacLean MA, Scott BE, Deziel BA, Nunnelley MC, Liberty AM, Gottschall-Pass KT, Neto CC, Hurta RA. North American cranberry (Vaccinium macrocarpon) stimulates apoptotic pathways in DU145 human prostate cancer cells in vitro. Nutr Cancer 2011;63(1):109-20.

13. Déziel B, MacPhee J, Patel K, Catalli A, Kulka M, Neto C, GottschallPass K, Hurta R. American cranberry (Vaccinium macrocarpon) extract affects human prostate cancer cell growth via cell arrest by modulating expression of cell cycle regulators. Food Funct 2012;3(5):556-64.

14. Vidlar A, Vostalova J, Ulrichova J,Student V, Stejskal D, Reichenbach R, Vrbkova J, Ruzicka F, Simanek V. The effectiveness of dried cranberries (Vaccinium macrocarpon) in men with lower urinary tract symptoms. BJN 2010;104:1181-9.

15. Sumegova K, Nagyova Z, Waczulikova I, Zitnanová I, Duracková Z. Activity of paraoxonase 1 and lipid profile in healthy children. Physiol Res 2007;56:351-3.

16. Jamaspishvili T, Kral M, Khomeriki I, Vyhnankova V, Mgebrishvili G, Student V, Kolar Z, Bouchal J. Quadriplex model enhances urinebased detection of prostate cancer. Prostate Cancer Prostatic Dis 2011;14:354-60.

17. Laxman B, Morris DS, Yu J, Siddiqui J, Cao J, Mehra R, Lonigro RJ, Tsodikov A, Wei JT, Tomlins SA, Chinnaiyan AM.A first-generation multiplex biomarker analysis of urine for the early detection of prostate cancer. Cancer Res 2008;68:645-9.

18. Tamura K, Furihata M, Tsunoda T, Ashida S, Takata R, Obara W, Yoshioka H, Daigo Y, Nasu Y, Kumon H, Konaka H, Namiki M, Tozawa K, Kohri K, Tanji N, Yokoyama M, Shimazui T, Akaza H, Mizutani Y, Miki T, Fujioka T, Shuin T, Nakamura Y, Nakagawa H. Molecular features of hormone-refractory prostate cancer cells by genome-wide gene expression profiles. Cancer Res 2007;67:5117-25.

19. Love HD, Booton SE, Boone BE, Breyer JP, Koyama T, Revelo MP, Shappell SB, Smith JR, Hayward SW. Androgen regulated genes in human prostate xenografts in mice: Relation to $\mathrm{BPH}$ and prostate cancer. PLoS ONE 2009;4(12):e8384.

20. Vaarala MH, Hirvikoski P, Kauppila S, Paavonen TK. Identification of androgen-regulated genes in humane prostate. Mol Med Reports 2012;6:466-72.

21. Jepson RG, Williams G, Craig JC. Cranberries for preventing urinary tract infections. Cochrane Database Syst Rev 2012; Issue 5, Art. No.:CD001321.

22. Vidlar A, Student V jr, Vostalova J, Fromentin E, Roller M, Simanek V, Student V. Cranberry fruit powder (FlowensTM) improves lower urinary tract symptoms in men: a double-blind, randomized, placebocontrolled study. World J Urol 2016;34(3):419-24.

23. Martinez-Pinero $L$, Schalken JA, Cabri $P$, Maisonobe $P$, de la Taille A. Triptocare Study Group. Evaluation of urinary prostate cancer antigen-3 (PCA3) and TMPRSS2-ERG score changes when starting androgen-deprivation therapy with triptorelin 6-month formulation in patients with locally advanced and metastatic prostate cancer. BJU Int 2014;114:608-16.

\section{Supplemental Material:}

The online version of this article (doi: 10.5507/ bp.2016.056) offers supplementary material. 